\title{
Research Paper: Strengthening Hospital Capacity for the COVID-19 Pandemic: Implementation of Electronic Patient Discharge
}

\author{
Mohaddeseh Sabethosseini Dokht ${ }^{1} \mathbb{C}$, Mehdi Yousefi ${ }^{1,2^{*}} \mathbb{C}$, Hamid Heidarian Miri ${ }^{3} \mathbb{C}$, Somayeh Fazaeli ${ }^{4} \mathbb{C}$, Hossein Ebrahimipour $^{1,2}$ \\ 1. Department of Health Economics and Management Science, School of Health, Mashhad University of Medical Sciences, Mashhad, Iran \\ 2. Social Determinants of Health Research Center, Mashhad University of Medical Sciences, Mashhad, Iran. \\ 3. Department of Biostatistics and Epidemiology, School of Public Health, Mashhad University of Medical Sciences, Mashhad, Iran. \\ 4. Department of Medical Records and Health Information Technology, School of Paramedical Sciences, Mashhad University of Medical Sciences, Mashhad, Iran
}

\begin{tabular}{|c|c|}
\hline $\begin{array}{l}\text { Use vour device toscan } \\
\text { and read the article online }\end{array}$ & ditation Sabethosseini Dokht M, Yousefi M, Heidarian Miri H, Fazaeli S, Ebrahimipour H. Strengthening Hospital Capacity \\
\hline 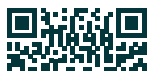 & $\begin{array}{l}\text { for the COVID-19 Pandemic: Implementation of Electronic Patient Discharge. Journal of Research \& Health. 2021; 11(5):305- } \\
\text { 312. http://dx.doi.org/10.32598/JRH.11.5.1802.1 }\end{array}$ \\
\hline 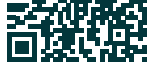 & doi'http://dx.doi.org/10.32598/JRH.11.5.1802.1 \\
\hline
\end{tabular}

(c) (1) (5)

Article info:

Received: 29 Jun 2020

Accepted: 15 Jun 2021

Publish: 01 Oct 2021

\section{Keywords:}

COVID-19, Six sigma,

Patient discharge, Hospital
A B S T R A C T

Background: Increasing hospital capacity to cover the service demands is an important priority during an epidemic or a pandemic. The aim of this study was to increase hospital capacity using the Six Sigma method to improve the patient discharge process.

Methods: This was a quantitative study. The Pre- and post-intervention study was conducted in a big hospital designated for COVID-19 patients. The patient discharge process was evaluated and improved based on seven sub-processes and following the Six Sigma model, including defining the problem, measuring time in each of the discharge stations, analysis times and process, improvement process, and control.

Results: Implementation of the electronic patient discharge led to a $51.9 \%$ decrease in discharge time from $7.3 \mathrm{~h}$ during the pre-intervention period to $3.8 \mathrm{~h}$ post-intervention $(\mathrm{P}<0.0001)$. According to the Sigma level, the yield and defects per million opportunities of the discharge process also improved to $55 \%$.

Conclusion: Increasing hospital capacity by improving the discharge time is a quick action to cover the demand created during pandemics. Also, about 32 beds can be obtained by applying the Six Sigma model to improve the discharge process in a short time and at a very low cost.

\section{"Corresponding Author:}

Mehdi Yousefi, PhD.

Address: Department of Health Economics and Management Science, School of Health, Mashhad University of Medical Sciences, Mashhad, Iran.

Phone: +98 (51) 31892509

E-mail:yousefimh@mums.ac.ir 


\section{Introduction}

$\mathbf{T}$

he current main global health problem is Coronavirus Disease 2019 (COVID-19) leading to acute respiratory illness [1]. Patients with symptoms, such as fever, dry coughs, and respiratory distress and also those with a more severe form of the disease are usually hospitalized for further treatment [2]. Accordingly, due to the high rate of transmission of this virus and its psychological effect, the increase in the number of visits to hospitals, and especially the need for special care were not unexpected [3]. Hence, the shortage of beds, equipment, and human resources in hospitals has been one of the most important challenges in providing hospital services to COVID-19 patients [4]. In addition, hospitals have been reported to be contaminated with viruses, where the transmission of the virus is many times higher than in other public places [5-7]. Consequently, the improvement of hospital processes with the aim of increasing hospital capacity along with reducing exposure is an important priority [8-12]. Also, the prolonged processes result in a delay in the admission process of a new patient and cause consequences, such as a decrease in the number of beds occupied by patients, hospital resources, and patients' satisfaction. To improve access to beds, the Joint Commission (JC) has stated that hospitals have designed processes that support patient flow throughout the hospital, measured available supply of beds and efficiency of patient care areas, reported measurements to leadership, and used data to drive improvements in patient flow processes. TJC has also recently started urging hospitals to use specific quality improvement tools to develop more reliable processes, including Lean and Six Sigma [10]. Therefore, improving the discharge process will lead to an increase in patient's satisfaction and the number of admissions, as well as faster room turnover rates [11-13]. This study intended to examine and improve the patient discharge process by implementing structural and educational interventions using the Six Sigma model.

\section{Methods}

\section{Study design and setting}

This quantitative pre-and post-intervention study without a control group was conducted in the Imam Reza Hospital Complex (IRHC). IRHC is a tertiary care teaching hospital with 1100 beds located in Mashhad, Iran. IRHC provides care to around 81,000 inpatients annually. IRHC was designated as the COVID-19 Referral Center, especially in Mashhad. The population of the study included patients in the general surgery wards, in which patients with COVID-19 were hospitalized. Random samples included 70 samples. Data of one month before the intervention (March 2020) were compared with one-month post-intervention (May 2020).

The sample size for the study was calculated based on QOL endpoints from previous studies [11]. Using a $95 \%$ confidence interval and $80 \%$ power, we calculated a sample size of $n=35$ in each group. Due to the reduction of elective surgeries during COVID-19, nurses in the surgical ward were transferred to COVID-19 wards.

\section{Data collection}

A total of 70 samples before and after the intervention were selected based on a previous similar study [14]. The main outcome of this study was reducing the average time from writing the discharge order by the physician until the patients receive the permission form to leave the hospital. The main outcome of this study was reducing the average time from writing the discharge order by the physician until the patients received the permission form to leave the hospital, for strengthening hospital capacity for the COVID-19 pandemic.

Data were collected by the stopwatch tool and through direct observation and face-to-face interviews with the relevant personnel and patients (or their families). In the first step, a preliminary review of the data and identification of discharge steps were performed through a team with the presence of those who were directly involved in the process, including the ward secretary experts, head nurses, billing staff, and nurses. The issues approved in the focus group were reviewed by a panel of 13 experts or the Six Sigma team. Secondly, after identifying the most important factors, the factors that delayed the discharge process were identified. Third, appropriate solutions to optimize the discharge process based on the various stations in the form of instructions for Electronic Patient Discharge (EPD) were suggested. The Six Sigma team included a ward secretary (changed to the Health Information Management (HIM) expert after the implementation of EPD), a nurse with at least 10 years of relevant work experience, a head nurse, a medical records officer, billing staff, and two faculty members with a relevant research background.

Notably, HIM experts worked on the classification of diseases and procedures to ensure they are standardized for clinical, financial, and legal uses; hence, they were responsible for the quality, integrity, and protection of patients' health information. HIM experts in Iran, typically have Bachelor's or Master's degrees in HIT [12]. Then, the on-the-job training 
method was used for the implementation of the EPD. The discharge process was modified based on the Six Sigma Model using the Define, Measure, Analyze, Improve, and Control (DMAIC) method. To identify the hospital discharge process and define the problem, the discharge process was defined in the seven stations.

\section{Statistical analysis}

As mentioned above, after determining the discharge stations, six Sigma steps were performed, including defining the problem, measuring the defect and error, analyzing the causes of a defect in each station, improving the discharge process by removing major causes, and controlling the process to ensure that the error does not recur. To further assess deviates of the process from total accuracy or perfection, the following items were also measured: Six Sigma scores, yield (percentage of discharges meeting the Sigma team goal (439 $\mathrm{min}$ ), and defects per million opportunities (number of defects in a process per one million opportunities). To determine the Sigma team goal, the total average time of discharge before the EPD was used as the Sigma team goal. The cases with a long average time of discharge were considered as defects in the discharge process. To calculate the defects per million opportunities, we implemented the following equation:

$$
\frac{\text { Number of defects }}{\text { Number of units } \times \text { Number of opportunities }}
$$

The process yield was calculated by subtracting the total number of defects from the total number of opportunities, dividing by the total number of opportunities, and finally, multiplying the result by 100 . To compare the time noted by the stations before and after the intervention in the surgery ward, first, the mean and standard deviation of each station were compared using the Mann-Whitney U test. To investigate the effect of the intervention, first, the difference between the two averages (before and after the intervention) and a 95\% confidence interval were calculated and compared. Excel 2016 and STATA 14 software were used to summarize and analyze the data.

\section{Results}

The findings showed that in the modified discharge process of patients with COVID-19, four out of the seven previous steps were eliminated. The most important change in the EPD process was changing the ward secretary to HIM experts. In the EPD, all discharge processes are performed without the presence of the patient and the medical record at the inpatient ward. In this process, the patient is discharged systematically and using the POS system, which is available to the HIM expert, all these processes are performed in the relevant inpatient ward. The HIM expert of each department should correct the defects of the medical records and deliver them to the medical records department within $48 \mathrm{~h}$ after the discharge. For the assessment of the HIMs' performance in the modified process, it received the scores of head nurse, patient accounting department, and medical records department, with a weight of $40 \%, 30 \%$, and $30 \%$, respectively. Table 1 presents some of the studied samples' characteristics according to the research period (pre- and post-intervention). There was no significant difference between the variables between the two periods.

Regarding the waiting time for discharge, all stations showed a significantly shorter waiting time $(\mathrm{P}<0.0001)$ in the post-intervention compared with the pre-intervention (Table 2). Based on the results before the interventions, the average discharge time before EPD was $439.73 \pm 69.64 \mathrm{~min}$, which decreased to $211.31 \pm 17.78$ min after EPD.

The Six Sigma score ranged between 1.37 and 1.55 with a yield of around $44.82 \%$ in the pre-intervention phase (DPMO: 542857). After the interventions, the number of errors reached zero, the Sigma score was less than 3.4, and the yield and defects per million opportunities of the discharge process also improved by $55 \%$.

\section{Discussion}

The aim of this study was to increase hospital capacity by decreasing the discharge time. The findings showed that the implementation of EPD led to a decrease in total discharge time to $228 \mathrm{~min}$. Considering the monthly discharge of 6,000 patients, the obtained discharge time resulted in an increase in the hospital bed capacity to about 32 active hospital beds with all facilities for the admission of patients with COVID-19. The yield and defects per million opportunities of the discharge process also improved by $55 \%$ in the post-intervention period and increased to $100 \%$. Numerous studies have used the Six Sigma model to decrease the average discharge time [10, 13, 15-17].

A study conducted at IRHC in 2013 showed a 26\% reduction in discharge time [18]. Due to the similar studied center, it can be stated that the findings of this study did not have sustainability. In this regard, there is evidence for the lack of demonstrable sustainability following the application of the Six Sigma model in healthcare settings [14, 18-20]. 
Table 1. The samples' characteristics in the pre- and post-intervention

\begin{tabular}{|c|c|c|c|c|}
\hline \multirow{2}{*}{ Variables } & \multirow{2}{*}{ Sub-variables } & \multicolumn{2}{|c|}{ No.(\%) } & \multirow{2}{*}{$\mathrm{P}\left(\mathrm{\chi}^{2}\right.$ test $)$} \\
\hline & & Pre-intervention & Post-intervention & \\
\hline \multirow{3}{*}{ Sex } & Male & $14(40)$ & $14(40)$ & \multirow{3}{*}{0.596} \\
\hline & & & & \\
\hline & Female & $21(60)$ & $21(60)$ & \\
\hline \multirow{7}{*}{ Age, years } & $1-10$ & $1(3)$ & 0 & \multirow{7}{*}{0.22} \\
\hline & $10-20$ & 0 & $2(5.7)$ & \\
\hline & $20-30$ & $3(8.6)$ & $3(8.6)$ & \\
\hline & $30-40$ & $6(17)$ & $12(34.3)$ & \\
\hline & $40-50$ & $11(31.4)$ & $7(20)$ & \\
\hline & $50-60$ & $6(17.1)$ & $8(22.9)$ & \\
\hline & $>60$ & $8(22.9)$ & $3(8.6)$ & \\
\hline \multirow{5}{*}{ Admission number } & First & $23(65)$ & $22(62.9)$ & \multirow{5}{*}{0.771} \\
\hline & Second & $23(65)$ & $9(25.7)$ & \\
\hline & Third & $23(65)$ & $2(5.7)$ & \\
\hline & Fourth & $23(65)$ & $2(5.7)$ & \\
\hline & Fifth and more & $23(65)$ & 0 & \\
\hline \multirow{7}{*}{ Length of stay (day) } & $1-3$ & $19(54.3)$ & $24(68.6)$ & \multirow{7}{*}{0.296} \\
\hline & $3-6$ & $8(22.9)$ & $8(22.9)$ & \\
\hline & $6-9$ & $2(5.7)$ & $2(5.7)$ & \\
\hline & & & & \\
\hline & $9-12$ & $2(5.7)$ & $1(2.9)$ & \\
\hline & $12-15$ & 0 & 0 & \\
\hline & $>15$ & $4(11.4)$ & 0 & \\
\hline \multirow{6}{*}{ Insurer Organization } & $\begin{array}{c}\text { Iran Health Insurance } \\
\text { Organization }\end{array}$ & $24(68.6)$ & $23(65.7)$ & \multirow{6}{*}{0.631} \\
\hline & $\begin{array}{l}\text { Social Security Orga- } \\
\text { nization }\end{array}$ & $8(22.9)$ & $10(28.6)$ & \\
\hline & $\begin{array}{l}\text { Military Health Insur- } \\
\text { ance }\end{array}$ & $1(2.9)$ & 0 & \\
\hline & $\begin{array}{l}\text { Imam Khomeini Relief } \\
\text { Foundation }\end{array}$ & 0 & 0 & \\
\hline & Uninsured & $1(2.9)$ & $2(5.7)$ & \\
\hline & Traffic accident & $1(2.9)$ & 0 & \\
\hline \multirow{3}{*}{ Need for social worker } & Needed & $13(37.1)$ & $9(25.7)$ & \multirow{3}{*}{0.22} \\
\hline & & & & \\
\hline & Not needed & $22(62.9)$ & $26(74.3)$ & \\
\hline
\end{tabular}


Table 2. Waiting time for discharge based on the requirements for patient's discharge order

\begin{tabular}{|c|c|c|c|c|c|}
\hline \multirow{3}{*}{ Stations } & \multirow{3}{*}{ Station Description } & \multicolumn{2}{|c|}{ Mean $\pm S D$} & \multirow{3}{*}{$\begin{array}{l}\text { Difference } \\
\text { (Confidence } \\
\text { Interval) }\end{array}$} & \multirow{3}{*}{$\mathbf{P}$} \\
\hline & & \multicolumn{2}{|c|}{ Time From Discharge, Minutes } & & \\
\hline & & Pre-intervention & Post-intervention & & \\
\hline 1 & $\begin{array}{l}\text { The time between } \\
\text { discharge order and } \\
\text { the completion of } \\
\text { the Patient Medical } \\
\text { Record (PMR) }\end{array}$ & $289.51 \pm 47.81$ & $197.68 \pm 13.74$ & $91.8(60,123)$ & 0.00001 \\
\hline 2 & $\begin{array}{l}\text { Waiting time to send } \\
\text { the PMR from the } \\
\text { ward }{ }^{*}\end{array}$ & $30.06 \pm 15.87$ & 0.00 & $30.06(24,35)$ & 0.00001 \\
\hline 3 & $\begin{array}{l}\text { The time needed to } \\
\text { receive the PMR by } \\
\text { the medical records } \\
\text { department }\end{array}$ & $16 \pm 4.49$ & 0.00 & $16(14,17)$ & 0.00001 \\
\hline 4 & $\begin{array}{l}\text { The time needed to } \\
\text { receive the PMR by } \\
\text { the financial services } \\
\text { department }\end{array}$ & $38.57 \pm 33.29$ & 0.00 & $38.57(27,50)$ & 0.00001 \\
\hline 5 & $\begin{array}{l}\text { The time needed to } \\
\text { start assessing the } \\
\text { PMR }\end{array}$ & $41.67 \pm 44.37$ & 0.00 & $41.67(28,55)$ & 0.00001 \\
\hline 6 & $\begin{array}{l}\text { The time needed to } \\
\text { issuance of the bill }\end{array}$ & $17.51 \pm 18.85$ & $8.83 \pm 13.35$ & $8.68(0.65,16)$ & 0.00001 \\
\hline 7 & $\begin{array}{l}\text { The time needed to is- } \\
\text { suance of the exit card }\end{array}$ & $6.41 \pm 9.19$ & $4.8 \pm 10.81$ & $1.6(-6,3)$ & 0.0052 \\
\hline $\begin{array}{l}\text { The whole dis- } \\
\text { charge process }\end{array}$ & $\begin{array}{l}\text { The time between } \\
\text { discharge order and is- } \\
\text { suance of the exit card }\end{array}$ & $439.73 \pm 69.64$ & $211.31 \pm 17.78$ & $228.4(192,264)$ & 0.00001 \\
\hline
\end{tabular}

* In stations 2-7, the time to start measures in the station is the time, at which the previous station ended its activity.

MPA

The yield and defects per million opportunities for assessing the improvement of the discharge process have been used in some studies. Vijay et al. attempted to reduce discharge time from $234 \mathrm{~min}$ to $135 \mathrm{~min}$ post-intervention. This study calculated the discharge sigma as the Six Sigma level of 95\% [21]. In the study by El-Banna, $70.2 \%$ of the patients were discharged within more than 50 min before the intervention, and the Six Sigma level of 1.11 was calculated [13]. However, the starting point and the end of the discharge process have been different from the current study. The first station showed a longer time in the discharge process. Due to the educational nature of the hospital, the role of medical assistants in the waiting time for discharge, especially at the first station, is very important in completing the summary sheets. A decline in the number of medical assistants directly increases the discharge time [22]. El -Banna in his study entitled "Improving Hospital Discharge Patients Using the Six Sigma Approach", has emphasized the impact of medical assistants in the ward [13].

Allen et al. used the Six Sigma model to improve discharge times by focusing on improving communication between nurses and physicians through the implementation of a standardized discharge form that led to a drop in discharge time from 3.3 to $2.8 \mathrm{~h}$ [23]. However, in this study, the waiting time for discharge regardless of the time needed for cost accounting and is not comparable to the current study.

This study, consistent with some other relevant studies $[10,24,25]$, confirmed the effectiveness of using the Six Sigma model to improve the patient discharge process. However, the application of this intervention for other hospitals requires some measures. First, it should be noted that the patient discharge process is very complex and the effectiveness of using the Six Sigma model requires good coordination between physicians, nurses, ancillary service staff, patients, and their families, and in some settings, the financial services department and medical records department $[17,26,27]$.

Other requirements include the existence of a Hospital Information System (HIS), the availability of sufficient hardware equipment, such as computers, scanners, and printers in each ward, the possibility of tracking medical 
records (non-electronic), the presence of IT professionals, and good coordination with the health insurance organizations. The use of information systems to increase the capacity of hospital beds by reducing bed allocation gaps has been proposed in various studies as one of the appropriate solutions [28].

The lack of adjusting for all possible confounders during the study, particularly in the post-intervention phase is the main limitation of this study. Assigning the IRHC for the reception and care of patients with COVID-19 was the most important confounder that could have affected the results. However, in the intervention used in the present study, some discharge stations were omitted, which did not associate with the considered type of patients; therefore, from the research team's point of view, this limitation did not have a significant effect on the effectiveness of the intervention.

Hospitals are the most complex building types. Each hospital is comprised of a wide range of services and functional units, which indicates large amounts of financial resources and time needed to build a hospital. However, prolonged and combined outbreaks can lead to the progressive spread of disease with rapidly increasing service demands that can potentially overwhelm the capacity of hospitals [29]. In these conditions, increasing hospital capacity through improving hospital processes is a quick action to cover the rapidly increasing service demands in an epidemic or a pandemic [30], which has been mentioned in various studies in recent decades $[31,32]$.

\section{Conclusion}

We showed that about 32 beds within the facility can be obtained by applying the Six Sigma model to improve the discharge process in a short time and at a very low cost, because creating an active and ready hospital bed is a very long process [31]. This process involves building the physical space and providing the equipment and personnel needed. This process may normally take several years for a small hospital in government systems. The present study, by modifying the hospital structure in a short period and also with the participation of all stakeholders, showed providing about 32 ready-to-serve hospital beds. However, by modifying some other steps of EPD, this time can be reduced again and increases the efficiency of hospital beds.

\section{Ethical Considerations}

\section{Compliance with ethical guidelines}

This study was approved by Ethicals Committee of Mashhad University of Medical Sciences (Code: IR.MUMS.REC.1399.109). This study was performed following the Declaration of Helsinki.

\section{Funding}

This study was supported by a grant (No. 922303) from the Mashhad University of Medical Sciences.

\section{Authors' contributions}

All authors equally contributed to preparing this article.

\section{Conflict of interest}

The authors declared no conflict of interest.

\section{References}

[1] Shi Y, Wang J, Yang Y, Wang Z, Wang G, Hashimoto K, et al. Knowledge and attitudes of medical staff in Chinese psychiatric hospitals regarding COVID-19. Brain Behav Immun Health. 2020; 4:100064. [DOI:10.1016/j.bbih.2020.100064] [PMID] [PMCID]

[2] Eghbali M, Negarandeh R, Froutan R. COVID-19 epidemic Hospital-level response. Nurs Pract Today. 2020; 7(2):81-3 [DOI:10.18502/npt.v7i2.2728]

[3] Carenzo L, Costantini E, Greco M, Barra FL, Rendiniello V, Mainetti M, et al. Hospital surge capacity in a tertiary emergency referral centre during the COVID-19 outbreak in Italy. Anaesthesia. 2020; 75(7):928-34. [DOI:10.1111/anae.15072] [PMID]

[4] Phua J, Weng L, Ling L, Egi M, Lim CM, Divatia JV, et al. Intensive care management of coronavirus disease 2019 (COVID-19): Challenges and recommendations. Lancet Respirat Med. 2020; 8(5):506-17. [DOI:10.1016/S2213-2600(20)30161-2]

[5] World Health Organization (WHO). Preparedness, prevention and control of Coronavirus Disease (COVID-19) for refugees and migrants in non-camp settings [Internet]. 2020 [Updated 2020 April 17]. Available from: https://www.who.int/ publications/i/item/preparedness-prevention-and-control-ofcoronavirus-disease-(covid-19)-for-refugees-and-migrants-innon-camp-settings

[6] Peeri NC, Shrestha N, Rahman MS, Zaki R, Tan Z, Bibi S, et al The SARS, MERS and novel coronavirus (COVID-19) epidemics, the newest and biggest global health threats: What lessons have we learned? Int J Epidemiol. 2020; 49(3):717-26. [DOI:10.1093/ ije/dyaa033] [PMID] [PMCID] 
[7] Lim T, Cho J, Kim BS. Predictions and measurements of the stack effect on indoor airborne virus transmission in a high-rise hospital building. Build Environ. 2011; 46(12):2413-24. [DOI:10.1016/j. buildenv.2011.04.015] [PMID] [PMCID]

[8] Chopra V, Toner E, Waldhorn R, Washer L. How should U.S hospitals prepare for Coronavirus Disease 2019 (COVID-19)? Ann Intern Med. 2020; 172(9):621-2. [DOI:10.7326/M20-0907] [PMID] [PMCID]

[9] Geiger-Brown J, Lipscomb J. The health care work environment and adverse health and safety consequences for nurses. Annu Rev Nurs Res. (1):191-231. [DOI:10.1891/07396686.28.191] [PMID]

[10] El-Eid GR, Kaddoum R, Tamim H, Hitti EA. Improving hospital discharge time: A successful implementation of Six Sigma methodology. Medicine (Baltimore). 2015; 94(12):e633-e. [DOI:10.1097/MD.0000000000000633] [PMID] [PMCID]

[11] Hopman J, Allegranzi B, Mehtar S. Managing COVID-19 in low- and middle-income countries. JAMA. 2020; 323(16):1549-50. [DOI:10.1001/jama.2020.4169] [PMID]

[12] Hesselink G, Zegers M, Vernooij-Dassen M, Barach P, Kalkman C, Flink M, et al. Improving patient discharge and reducing hospital readmissions by using Intervention Mapping. BMC Health Serv Res. 2014;14(1):389. [DOI:10.1186/14726963-14-389] [PMID] [PMCID]

[13] El-Banna MA. Improving patients discharge process in hospitals by using six sigma approach. World Acad Sci Eng Technol. 2012; 6(8):100-9. https://d1wqtxts1xzle7.cloudfront.net/57345468/Improving-Patients-Discharge-Processin-Hospitals-by-using-Six-Sigma-Approach-with-coverpage-v2.pdf?Expires $=\mathrm{A}$

[14] Ebrahimipour H, Vajaee A, Nouri GA, Esmaeili H, Jamili $\mathrm{S}$. [Studying waiting time of patient during discharge process in clinical departments of Imam Reza Hospital affiliated with Mashhad University of Medical Science in 2014 (Persian)]. J Hospital. 2015; 14(1):117-25. http://jhosp.tums.ac.ir/article1-5327-fa.html

[15] Niemeijer GC, Trip A, Ahaus KT, Does RJ, Wendt KW. Quality in trauma care: Improving the discharge procedure of patients by means of Lean Six Sigma. J Trauma. 2010; 69(3):614-9. [DOI:10.1097/TA.0b013e3181e70f90] [PMID]

[16] Mandahawi N, Al-Shihabi S, Abdallah AA, Alfarah YM. Advantage $\mathrm{C}$. Reducing waiting time at an emergency department using design for Six Sigma and discrete event simulation. Int J Six Sigma Compet Advant. 2010; 6(1-2):91-104. [DOI:10.1504/IJSSCA.2010.034858]

[17] Ahmed S, Manaf NH, Islam R. Effects of Lean Six Sigma application in healthcare services: A literature review. Rev Environ Health. 2013; 28(4):189-94. [DOI:10.1515/ reveh-2013-0015] [PMID]

[18] Breslin SE, Hamilton KM, Paynter J. Deployment of lean six sigma in care coordination: An improved discharge process. Prof Case Manag. 2014; 19(2):77-83. [DOI:10.1097/ NCM.0000000000000016] [PMID]

[19] Liberatore MJ. Six Sigma in healthcare delivery. Int J Health Care Qual Assur. 2013; 26(7):601-26. [DOI:10.1108/ IJHCQA-09-2011-0054] [PMID]

[20] DelliFraine JL, Langabeer JR, Nembhard IM. Assessing the evidence of Six Sigma and Lean in the health care industry.
Qual Manag Health Care. 2010; 19(3):211-25. [DOI:10.1097/ QMH.0b013e3181eb140e] [PMID]

[21] Vijay SA. Reducing and optimizing the cycle time of patients discharge process in a hospital using six sigma dmaic approach. Int J Qual Res. 2014; 8(2):169-82. http:/ / www.ijqr. net/journal/v8-n2/3.pdf

[22] Saretsky G. The OEO P.C. experiment and the John Henry effect. Phi Delta Kappan. 1972; 53(9):579-81. https:/ / www.jstor.org/stable/20373317

[23] Allen TT, Tseng SH, Swanson K, McClay MA. Improving the hospital discharge process with Six Sigma methods. Q Eng. 2009; 22(1):13-20. [DOI:10.1080/08982110903344812]

[24] Ajami S, Ketabi S. An analysis of the average waiting time during the patient discharge process at Kashani Hospital in Esfahan, Iran: A case study. Health Inf Manag. 2007; 36(2):37-42. [DOI:10.1177/183335830703600207] [PMID]

[25] Udayai K, Kumar P. Implementing Six Sigma to improve hospital discharge process. Int J Pharm Sci Res. 2012; 3(11):4528-32. [DOI:10.13040/IJPSR.0975-8232]

[26] Watts R, Gardner H. Nurses' perceptions of discharge planning. Nurs Health Sci. 2005; 7(3):175-83. [DOI:10.1111/ j.1442-2018.2005.00229.x] [PMID]

[27] Matos J, Rodrigues PP, editors. Modeling decisions for hospital bed management: A review. Paper presented at: International Conference on Health Informatics. 17-18 January 2011; Rome, Italy. [DOI:10.5220/0003135005040507]

[28] Verderber S. Innovations in hospital architecture. London: Routledge; 2010. [DOI:10.4324/9780203855751]

[29] Grimm CA. Hospital experiences responding to the COVID-19 pandemic: Results of a national pulse survey march 2327, 2020 [Internet]. 2020 [Updated 2020 April 22]. Available from: https:// psnet.ahrq.gov/issue/hospital-experiences-responding-covid-19-pandemic-results-national-pulse-surveymarch-23-27

[30] Ortiga B, Salazar A, Jovell A, Escarrabill J, Marca G, Corbella $X$. Standardizing admission and discharge processes to improve patient flow: A cross sectional study. BMC Health Serv Res. 2012; 12:180. [DOI:10.1186/1472-6963-12-180] [PMID] [PMCID]

[31] Nowak NA, Rimmasch H, Kirby A, Kellogg C. Right care, right time, right place, every time. Healthc Financ Manage. 2012; 66(4):82-8. [PMID]

[32] Grunden N, Hagood C. Lean-led hospital design: Creating the efficient hospital of the future. New York: CRC Press; 2012. [DOI:10.1201/b11766] 
This Page Intentionally Left Blank 